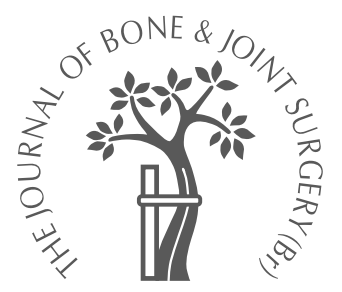

A. W. Blom, J. Brown,

A. H. Taylor,

G. Pattison,

S. Whitehouse,

G. C. Bannister

From Southmead

Hospital, Bristol, England

A. W. Blom, PhD, FRCS

(Trauma \& Orth), Lecturer, Specialist Registrar

J. Brown, MRCS, Clinical

Fellow

A. H. Taylor, FRCS (Trauma \& Orth), Specialist Registrar

G. Pattison, FRCS (Trauma

\& Orth), Specialist Registrar

S. Whitehouse, $\mathrm{PhD}$

Statistician

G. C. Bannister, MCh, Orth, MD, FRCS Orth, Consultant Avon Orthopaedic Centre, Southmead Hospital, Westbury-on-Trim, Bristol BS10 5NB, UK.

Correspondence should be sent to Mr A. W. Blom at 23 Old Sneed Avenue, Stoke

Bishop, Bristol BS9 1SD, UK.

(C)2004 British Editorial Society of Bone and Joint Surgery doi:10.1302/0301-620X.86B5. $14887 \$ 2.00$

$J$ Bone Joint Surg [Br] 2004;86-B:688-91.

Received 18 August 2003;

Accepted after revision

20 January 2004

\title{
Infection after total knee arthroplasty
}

The aim of our study was to determine the current incidence and outcome of infected total knee arthroplasty (TKA) in our unit comparing them with our earlier audit in 1986, which had revealed infection rates of $4.4 \%$ after 471 primary TKAs and $15 \%$ after 23 revision TKAs at a mean follow-up of $\mathbf{2 . 8}$ years. In the interim we introduced stringent antibiotic prophylaxis, and the routine use of occlusive clothing within vertical laminar flow theatres and $\mathbf{0 . 0 5 \%}$ chlorhexidine lavage during arthroplasty surgery.

We followed up 931 primary TKAs and 69 revision TKAs for a mean of 6.5 years (5 to 8). Patients were traced by postal questionnaire, telephone interview or examination of case notes of the deceased.

Nine $(1 \%)$ of the patients who underwent primary TKA, and four $(5.8 \%)$ of those who underwent revision TKA developed deep infection. Two of nine patients $(22.2 \%)$ who developed infection after primary TKA were successfully treated without further surgery. All four of the patients who had infection after revision TKA had a poor outcome with one amputation, one chronic discharging sinus and two arthrodeses.

Patients who underwent an arthrodesis had comparable Oxford knee scores to those who underwent a two-stage revision. Although infection rates have declined with the introduction of prophylactic measures, and more patients are undergoing TKA, the outcome of infected TKA has improved very little.

Infection after total knee replacement is an infrequent, but a serious complication which is difficult to treat. The reported incidence of infection varies between $0.5 \%$ and $12 \% .^{1-5}$ Hinged prostheses, rheumatoid arthritis and previous knee surgery are all associated with an increased risk of infection. ${ }^{5}$ Treatment options include long-term antibiotics, ${ }^{6,7}$ arthroscopic washout, ${ }^{8}$ open debridement, ${ }^{6,9}$ resection arthroplasty, ${ }^{6}$ one-stage revision, ${ }^{6,10,11}$ twostage revision, ${ }^{6,12-14}$ arthrodesis ${ }^{6}$ and amputation.

We performed an audit on all primary and revision total knee arthroplasties (TKAs) undertaken in our unit between 1993 and 1996. Our aim was to compare our current results with those of a previous study from our unit which was published in $1986,{ }^{4}$ taking into account the introduction of laminar flow theatres, effective antibiotic prophylaxis, ${ }^{15}$ occlusive clothing, ${ }^{16}$ and $0.005 \%$ chlorhexidine lavage $^{17}$ and quantified the outcome of infected TKA after a variety of treatments. A total of 27 consultant surgeons, their registrars and senior house officers, as well as clinical fellows, research fellows and visiting surgeons, carried out the operations. The theatres at the Avon Orthopaedic Centre are solely for elective orthopaedic use. There is no agreed policy on prophylaxis for deep venous thrombosis; it remains at the discretion of the individual surgeon and may include both pharmacological and mechanical measures.

\section{Patients and Methods}

A postal questionnaire was sent to all patients who underwent primary (956) or revision TKA (75) at our unit between January 1993 and December 1996, five to eight years following surgery. All who failed to reply were sent a second questionnaire. Those who responded to neither questionnaire were contacted by telephone. The notes of all deceased patients were traced.

Patients were asked whether they had had any suspicion of infection in the joint or wound after the knee surgery. If they replied in the affirmative, they were asked if they had 1) a reddened or inflamed wound whilst in hospital requiring antibiotics; 2) a reddened or inflamed wound after leaving hospital requiring antibiotics from their general practitioner; 
Table I. Details of the 9 infected primary TKAs

\begin{tabular}{|c|c|c|c|c|c|c|c|c|c|}
\hline Case & Age & Gender & Risk factors & $\begin{array}{l}\text { Timing of } \\
\text { infection }\end{array}$ & Culture & Sensitivity & Antibiotic $\neq$ & $\begin{array}{l}\text { Type of } \\
\text { surgeryt }\end{array}$ & Outcome \\
\hline 1 & 38 & M & $\begin{array}{l}\text { Previous: upper tibial } \\
\text { osteotomy }\end{array}$ & 23 months & CNS* & Flucloxacillin & IV $A B$ & AW, 2SR & Success \\
\hline 2 & 69 & $\mathrm{~F}$ & - & 9 months & CNS & Flucloxacillin & IV AB & 2SR & Success \\
\hline 3 & 68 & M & - & 18 days & CNS & Ciprofloxacin & IV AB & 2SR & Success \\
\hline 4 & 62 & M & - & 3 days & $\begin{array}{l}\text { Staphylococcus epider- } \\
\text { midis, Streptococcus }\end{array}$ & $\begin{array}{l}\text { Flucloxacillin, } \\
\text { Benzylpenicillin }\end{array}$ & IV $A B$ & $D, F$ & Success \\
\hline 5 & 76 & $\mathrm{~F}$ & Malignancy: Ca Colon & 35 months & Staphylococcus & $\begin{array}{l}\text { Flucloxacillin, } \\
\text { Benzylpenicillin, } \\
\text { Erythromycin }\end{array}$ & IV $A B$ & AW, D & Success \\
\hline 6 & 82 & $\mathrm{~F}$ & - & 14 days & $\begin{array}{l}\text { Peptostreptococcus, } \\
\text { CNS }\end{array}$ & $\begin{array}{l}\text { Metronidazole, } \\
\text { Flucloxacillin }\end{array}$ & IV $A B$ & - & Arthrodesis \\
\hline 7 & 66 & $\mathrm{~F}$ & $\begin{array}{l}\text { Leg ulcers, rheumatoid } \\
\text { arthritis }\end{array}$ & 28 months & CNS & Flucloxacillin & IV $A B$ & - & Arthrodesis \\
\hline 8 & 75 & M & - & 4 months & $\begin{array}{l}\text { Staphylococcus aureus, } \\
\text { Enterococcus, Staphylo- } \\
\text { coccus epidermidis }\end{array}$ & $\begin{array}{l}\text { Flucloxacillin, } \\
\text { Vancomycin, Van- } \\
\text { comycin }\end{array}$ & IV AB & AW, 1SR & Chronic infection \\
\hline 9 & 80 & $\mathrm{~F}$ & $\begin{array}{l}\text { Surgery: Enders nails } \\
\text { for tibial fracture }\end{array}$ & 41 months & Non growth & - & IV $A B$ & - & Chronic infection \\
\hline
\end{tabular}

* coagulase-negative staphylococcus

† AW, arthroscopic washout; D, debridement; F, flap; 1SR, one-stage revision 2SR, two-stage revision

₹ IV AB intravenous antibiotics

Table II. Details of the 4 infected revision TKAs

\begin{tabular}{|c|c|c|c|c|c|c|c|c|c|c|}
\hline Case & Age & Gender & $\begin{array}{l}\text { First revision } \\
\text { operation }\end{array}$ & Risk factors & $\begin{array}{l}\text { Timing of } \\
\text { infection }\end{array}$ & Culture & Sensitivity & Antibiotic§ & $\begin{array}{l}\text { Type of } \\
\text { surgery* }\end{array}$ & Outcome \\
\hline 1 & 66 & $\mathrm{~F}$ & Aseptic loosening & Revision & 13 days & $\begin{array}{l}\text { Staphylococcus } \\
\text { epidermidis }\end{array}$ & $\begin{array}{l}\text { Ciprofloxacin, } \\
\text { Rifampicin, } \\
\text { Clindamycin }\end{array}$ & IV $A B$ & $\mathrm{AW}, \mathrm{R} \dagger$ & Arthrodesis \\
\hline 2 & 74 & $\mathrm{~F}$ & Aseptic loosening & Revision & 12 months & Staphylococcus & Flucloxacillin & IV $A B$ & $\mathrm{D}$ & Arthrodesis \\
\hline 3 & 72 & $\mathrm{~F}$ & $\begin{array}{l}\text { Peri-prosthetic } \\
\text { fracture }\end{array}$ & $\begin{array}{l}\text { Revision. ORIF } \\
\text { fracture. Venous } \\
\text { ulcers }\end{array}$ & 10 months & Streptococcus & Ampicillin & IV $A B$ & AW & Chronic infection \\
\hline 4 & 72 & M & $\begin{array}{l}\text { Peri-prosthetic } \\
\text { fracture }\end{array}$ & $\begin{array}{l}\text { Revision. ORIF } \\
\text { fracture. } \\
\text { Previous wound } \\
\text { infection }\end{array}$ & 19 days & $\begin{array}{l}\text { Staphylococcus } \\
\text { aureus }\end{array}$ & $\begin{array}{l}\text { Flucloxacillin, } \\
\text { Erythromycin }\end{array}$ & IV AB & $A W, D, R \neq$ & $\begin{array}{l}\text { Above-knee } \\
\text { amputation }\end{array}$ \\
\hline
\end{tabular}

* AW, arthroscopic washout; D, debridement; 2SR, two-stage revision

$\dagger$ femoral component

‡ custom prosthesis

$\S$ IV $A B$ intravenous antibiotics

3) an infection which required re-admission to hospital for further treatment or investigation; 4) a deep infection (inside the joint) requiring further surgery; or 5) any other (please specify).

Patients were also asked to complete an Oxford Knee Score questionnaire. ${ }^{18}$ The notes of all those who replied and all deceased patients were examined.

\section{Results}

The details of patients with infected TKAs are shown in Table I for primary and in Table II for revision TKAs.

Primary total knee arthroplasty. During the period of the study 956 primary TKAs were performed on 956 patients.

We contacted 831 patients by questionnaire or telephone. Of the remaining 125 patients, 100 had died and 25 were lost to follow-up. Follow-up assessments were completed for 931 of the 956 patients with a mean follow-up of 6.5 years (5 to 8$)$. Infection was identified in nine patients $(1 \%)$. In eight cases an organism was identified from a wound swab. In all patients it was a staphylococcus and in seven it was sensitive to Flucloxacillin. Four patients $(0.42 \%)$ had undergone revision of their primary TKA for deep infection; three having a two-stage revision with no sign of residual infection at the latest review; their Oxford knee scores were 54, 41 and 34 respectively (an Oxford knee score of 12 is symptom free and 60 is disabled). The fourth underwent an arthroscopic washout followed by a one-stage revision. This patient still had chronic deep infection at his latest review and an Oxford knee score of 51.

Two patients underwent radical debridement, one needing a gastrocnemius flap to obtain cover but in neither was there evidence of infection at their latest review. The Oxford knee scores of these two patients were 41 and 34. Arthrodesis of the knee was carried out on two patients. At their latest review they had no sign of infection and their knee scores were 35 and 36 . One patient, having refused surgery, was treated with long-term antibiotics to suppress the infection. At his latest review chronic infection persisted with an 
Oxford knee score of 36 . Only two of nine (22.2\%) prostheses were retained without evidence of deep infection.

Revision total knee arthroplasty. Revision TKA (75) was carried out on 75 patients during the period of the study. We traced 59 patients; ten had died and six $(8 \%)$ were lost to follow-up. Our follow-up was 69 of 75 patients between five and eight years after surgery. Four patients (5.8\%) developed deep infection. In all cases an organism was identified from a wound stab. The organism was staphylococcus aureus in two cases, staphylococcus epidermidis in one and streptococcus in one. These organisms were treated with the appropriate intravenous antibiotics to which they were sensitive.

Two patients were treated with an arthroscopic washout followed by a two-stage revision. In both cases this was unsuccessful. One patient required an arthrodesis of the knee and one an above-knee amputation. The former had an Oxford knee score of 43. One was treated with an open debridement, followed by an arthrodesis with no sign of infection four years later and a knee score of 40 . The one remaining patient underwent an arthroscopic washout, debridement and long-term antibiotics but a chronic discharging sinus was still present at the latest review. The knee score was 39 .

\section{Discussion}

This is a retrospective study of primary TKA with a followup of $97 \%$, and of revision TKA with a follow-up of $92 \%$. Both groups were reviewed at a mean follow-up of 6.5 years. We accept that although the number of patients lost to follow-up was small, some could have had a deep infection. If all patients lost to follow-up were infected, the rate of infection amongst primary TKAs would have been $4 \%$.

Our questionnaire may fail to detect patients with latent infection beneath well-healed wounds but with non-specific symptoms leading to a poor outcome. A prospective study obtaining wound swabs from all revision cases would have answered this question. Our known infection rates of $1 \%$ after primary and $5.8 \%$ after revision TKA are comparable with published reports. A similar study carried out at our unit a decade ago showed an infection rate of $4.4 \%$ after primary and $15 \%$ after revision TKA. ${ }^{4}$ In the interim we have adopted the measures of laminar flow ventilation in the operating theatres, chlorhexidine lavage and occlusive clothing for all theatre personnel.

These measures have all been shown in recent studies to decrease wound contamination. ${ }^{16,17,19}$ The outcome of patients with deep infection after primary TKA, was poor with only two of nine $(22.2 \%)$ patients retaining their prosthesis free from infection. Bengtson ${ }^{5}$ reported similar results in a much larger cohort of patients from Sweden, with only $20 \%$ recovering from infection with a functioning prosthesis.

The outcome of the four cases infected after revision TKA was even worse. None retained his prosthesis free from infection. Hanssen, Trousdale and Osmon ${ }^{20}$ reported similar poor results with infection following revision TKAs. Their 24 patients in whom revision TKA was followed by infection, underwent a mean of 9.3 surgical procedures; ten ended with successful arthrodeses; four patients underwent above-knee amputations; only one patient ultimately retained an uninfected prosthesis. ${ }^{20}$

In our study, Oxford knee scores were universally poor after infection in both primary and revision TKAs. The best score was 34 . The scale of the Oxford knee score ranges between 12 (best) and 60 (worst). Most of our infected patients had a score worse than the mid-value (36) at their latest review.

Arthroscopic washout was an ineffective method of treatment. Waldman et $\mathrm{al}^{8}$ observed that arthroscopic washout was less effective than open debridement. Our two infected primary TKAs who were treated with early radical debridement retained their prostheses and had no sign of infection at their latest follow-up. Our policy now is to proceed to early radical debridement and not to perform arthroscopic washout. Patients who underwent arthrodesis did no worse in terms of their Oxford knee scores than those who underwent two-stage revisions and did better with regard to eradication of infection. Wilson et $\mathrm{al}^{21} \mathrm{com}-$ pared various modalities of treatment for infected TKA. Four of their patients underwent arthrodesis and in all cases the patients were free of both pain and infection, but mobilised poorly.

Our follow-up of between five and eight years is longer than most comparable studies. During this study period, infection after primary TKA was rare but devastating and invariably led to a poor outcome. Infection after revision TKA was more common and when it occurred, the outlook was always bad. Our recommendation is that arthroscopic washout should not be attempted, but that all infected TKAs should be treated initially by radical debridement. If that fails, either a complete revision procedure or an arthrodesis is our chosen procedure.

No benefits in any form have been received or will be received from a commercial party related directly or indirectly to the subject of this article.

\section{References}

1. Salvati EA, Robinson RP, Zeno SM, et al. Infection rates after 3175 total hip and total knee replacements performed with and without a horizontal unidirectional filtered air-flow system. J Bone Joint Surg [Am] 1982;64-A:525-35.

2. Poss R, Thornhill TS, Ewald FC, et al. Factors influencing the incidence and outcome of infection following total joint arthroplasty. Clin Orthop 1984;182:117-26.

3. Grogan TJ, Dorey F, Rollins J, Amstutz HC. Deep sepsis following total knee arthroplasty. J Bone Joint Surg [Am] 1986;68-A:226-34.

4. Johnson DP, Bannister GC. The outcome of infected arthroplasty of the knee. J Bone Joint Surg [Br] 1986;68-B:289-91.

5. Bengtson S, Knutson K. The infected knee arthroplasty: a 6-year follow-up of 357 cases. Acta Orthop Scand 1991;62:301-11.

6. Segawa H, Tsukayama DT, Kyle RF, Becker DA, Gustilo RB. Infection after total knee arthroplasty: a retrospective study of the treatment of eighty-one infections. J Bone Joint Surg [Am] 1999;81-A:1434-45.

7. Segreti J, Nelson JA, Trenholme GM. Prolonged suppressive antibiotic therapy for infected orthopedic prostheses. Clin Infect Dis 1998;27:711-13.

8. Waldman BJ, Hostin E, Mont MA, Hungerford DS. Infected total knee arthroplasty treated by arthroscopic irrigation and debridement. J Arthroplasty 2000;15: $430-5$ 
9. Schoifet SD, Morrey BF. Treatment of infection after total knee arthroplasty by debridement with retention of components. J Bone Joint Surg [Am] 1990;72-A:1383-90.

10. Goksan SB, Freeman MA. One-stage reimplantation for infected total knee arthroplasty. J Bone Joint Surg [Br] 1992;74-B:78-82.

11. Nelson CL. Primary and delayed exchange for infected total knee arthroplasty. Am J Knee Surg 2001;14:60-4.

12. Insall JN, Thompson FM, Brause BD. Two-stage reimplantation for the salvage of infected total knee arthroplasty. J Bone Joint Surg [Am] 1983;65-A:1087-97.

13. Hirakawa K, Stulberg BN, Wilde AH, Bauer TW, Secic M. Results of two-stage reimplantation of the infected total knee arthroplasty. J Arthroplasty 1998;13:22-7.

14. Lonner JH, Beck TD Jr, Rees H, Roullet M, Lotke PA. Results of two-stage revision of the infected total knee arthroplasty. Am J Knee Surg 2001;14:65-7.

15. Bannister GC, Auchincloss JR, Johnson DP, Newman JH. The timing of tourniquet application in relation to prophylactic antibiotic administration. J Bone Joint Surg [Br] 1988;70-B:322-4.
16. Hubble MJ, Weale AE, Perez J, et al. Clothing in laminar-flow operating theatres $J$ Hosp Infect 1996;32:1-7.

17. Taylor GJS, Leeming JP, Bannister GC. Effect of antiseptics, ultraviolet light and lavage on airborne bacteria in a model wound. J Bone Joint Surg [Br] 1993;75-B: 724-80.

18. Dawson J, Fitzpatrick R, Murray D, Carr A. Questionnaire on the perceptions of patients about total knee replacement. J Bone Joint Surg [Br] 1998;80-B:63-9.

19. Lidwell OM. Air, antibiotics and sepsis in replacement joints. J Hosp Infect 1988;11 (Suppl C):18-40.

20. Hanssen AD, Trousdale RT, Osmon DR. Patient outcome with reinfection following reimplantation for the infected total knee arthroplasty. Clin Orthop 1995;321: 55-67.

21. Wilson MG, Kelley K, Thornhill TS. Infection as a complication of total knee replacement arthroplasty: risk factors and treatment in sixty-seven cases. J Bone Joint Surg [Am] 1990;72-A:878-83. 